\section{Kidney \\ Blood Pressure Research}

\title{
IgA Enhances IGF-1 Mitogenic Activity Via Receptor Modulation in Glomerular Mesangial Cells: Implications for IgA- Induced Nephropathy
}

\author{
Amal Al-Eisa Gursev S. Dhaunsi \\ Department of Pediatrics, Faculty of Medicine, Kuwait University, Jabriya, Kuwait
}

\section{Key Words}

IgA • Nephropathy $・$ IGF-1 $・$ IGF-1 receptor • Mesangial cells

\begin{abstract}
Background/Aim: Glomerulonephritis due to mesangial proliferation is responsible for renal dysfunction in IgA nephropathy (IgAN), however molecular mechanisms of pathogenesis are not well known. We examined the effect of IgA on Insulin-like Growth Factor-1 (IGF-1) activity, a potent mitogen with vital role in growth and development of children, and IGF-1 receptor (IGF-1R) in cultures of glomerular mesangial cells (GMC). Methods: GMC were isolated from rat kidneys using sieving and enzymatic digestion of tissue homogenates, and cultured in RPMI 1640 medium. GMC cultures were treated with $\mathrm{IgA}(0-10 \mu \mathrm{g} / \mathrm{ml})$ in the presence or absence of IGF-1 and fetal bovine serum (FBS), and BrdU incorporation was measured. IGF-1 levels were assayed along with real-time PCR quantification of IGF-1R mRNA. Results: Treatment of GMC with IgA $(5-10 \mu \mathrm{g} / \mathrm{ml})$ significantly $(p<0.01)$ increased the BrdU incorporation in the presence or absence of FBS or IGF-1. IgA-mediated effects were more pronounced in IGF-1 treated cells that were significantly $(p<0.01)$ blocked by pretreatment of cells with IGF-1 receptor antibody or genistein. IgA significantly increased the levels of IGF-1 in culture supernatants and GMC homogenates. IGF-1R mRNA was significantly $(p<0.01)$ increased in IgA treated cells particularly by co-treatment with IGF-1. Conclusion: These findings show that IgA enhances the IGF-1 activity in GMC via stimulation of IGF-1R gene transcription and suggest a role for IGF-1 in pathogenesis of IgAN.
\end{abstract}




\section{Kidney Blood Pressure Research}

\section{Introduction}

IgA-mediated nephropathy (IgAN) is a common glomerulonephritis disorder affecting children in different parts of the world including Kuwait [1-3]. Clinical presentation of IgAN includes the development of painless hematuria concurrent with the onset of a viral pharyngitis, gastroenteritis, or pneumonia. Major risk factors linked to progressive IgA disease include hypertension, proteinuria, male gender, and persistent microscopic hematuria [4-6]. Glomerulonephritis involves thickening of the glomerular basement membrane, mesangial cell proliferation, and the accumulation of mesangial extracellular matrix leads to obstruction of the glomerular capillary causing loss of glomerular filtration and kidney dysfunction [7, 8]. Mesangial cells serve a number of functions in the renal glomerular capillary including structural support of the capillary tuft, modulation of glomerular hemodynamics, and a phagocytic function allowing removal of macromolecules and immune complexes [9]. When exposed to an injurious stimulus, the mesangial cell responds by cellular proliferation and matrix synthesis leading to an increase in mesangial cells and matrix accumulation that ultimately progresses to glomerulosclerosis during development of membranoproliferative diseases such as IgA nephropathy. Though exact mechanisms of IgA nephropathy still remain unclear, deposition of IgA in mesangial cells has been implicated with evidence for a variable participation of monomeric, polymeric or secretory forms of IgA in development and progression of nephropathy [10,11].

Prominent feature of glomerular diseases including IgA nephropathy is membranoproliferative glomerulonephritis and in experimental models of nephritis, mesangial cell proliferation frequently precedes and is linked to the increase of extracellular matrix in the mesangium and glomerulosclerosis. Factors that control mesangial cell function include cytokines and growth mediators, matrix components including integrins, and interactions with other cells such as the endothelial and epithelial cells [12-15].Though a role for PDGF in progressive glomerulosclerosis has been suggested earlier with use of antibodies to PDGF as an antiproliferative therapeutic tool, yet role of growth factors in IgAN has remained poorly studied. Insulin-like growth factor-1 (IGF-1) has been shown to regulate proliferation of glomerular mesangial cells and polymorphisms of IGF-1 and IGF-1 receptor have recently been shown to contribute toward pathologic progression of childhood IgA nephropathy [16]. These studies suggest that IGF-1 might have an important role in development and progression of IgA-mediated nephropathy. Normal human, rat, and mouse mesangial cells in primary culture possess high affinity receptors for IGF-1 and few if any insulin receptors. Mesangial cells in culture also produce IGF-1 and IGF-1-binding protein(s). IGF-1 is mitogenic for mesangial cells, thus IGF-1 may act as an autocrine or paracrine factor participating in the regulation of mesangial cell function. Transgenic mice expressing increased levels of growth hormone and growth hormone-releasing factor exhibit high levels of circulating IGF-1 and develop glomerulosclerosis. Mesangial cell proliferation is a common hallmark of many glomerular diseases, including IgAN.

The exact mechanisms inducing cell proliferation in IgA-mediated glomerulosclerosis are not completely understood, and it remains to be determined whether IGF-1 plays a role in this process. Glomerular mesangial cells have IGF-1 receptors to exhibit mitogenic response to IGF I and this study was designed to examine the effect of IgA on IGF-1 system in cultures of rat glomerular mesangial cells in order to understand the role of IGF-1 in molecular mechanisms of IgAN.

\section{Materials and Methods}

\section{Materials}

Bovine serum albumin (BSA), penicillin / streptomycin and fetal bovine serum (FBS) were purchased from Sigma Chemical Company (St. Louis, MO). DMEM-Ham's F-12 (1:1) and trypsin-EDTA were from GIBCO (Grand Island, NY). IGF-1 and genistein were purchased from Sigma Chemical Co. Primaria tissue culture plates were obtained from Falcon Becton Dickinson (Oxnard, CA). Purified human colostrum IgA 


\section{Kidney \\ Blood Pressure Research}

(a secretory form of IgA) was procured from Sigma Chemical Company while monoclonal antibody against IGF-1 receptor was purchased from Santa Cruz Biotechnology, Inc. (Dallas, TX, USA). All other reagents of highest quality available were purchased from Sigma or Calbiochem.

\section{Isolation and primary culture of mesangial cells}

Glomerular mesangium were isolated and cultured initially in a selective mesangial cell culture medium RPMI 1640 supplemented with D-valine instead of L-valine and with $20 \%$ fetal calf serum. Renal mesangial cells were isolated from and cultured as described previously [17]. Kidney cortex were dissected from male Sprague-Dawley rats, chopped on ice and passed through a series of nylon meshes of graded pore sizes $(150,105$, and $77 \mu \mathrm{mol} / \mathrm{L})$ by applying gentle pressure and repeated washing with phosphatebuffered saline (PBS; pH 7.4) supplemented with antibiotics $(100 \mathrm{U} / \mathrm{mL}$ of penicillin and $100 \mu \mathrm{g} / \mathrm{mL}$ of streptomycin). Glomeruli collected from the final $77 \mu \mathrm{mol} / \mathrm{L}$ collection sieve were rinsed and digested with collagenase (100 mg/100 mL) for 15 minutes prior to plating in Dulbecco's modified Eagle's medium (DMEM; Life Technologies) containing 20\% fetal bovine serum (FBS; Life Technologies), antibiotics, 24 mmol/L $\mathrm{NaHCO}_{3}$, and $20 \mathrm{mmol} / \mathrm{L}$ HEPES. Mesangial cells obtained from glomerular outgrowths were treated with experimental agents. Positive immunofluorescent staining for smooth muscle $\alpha$-actin and negative staining for von Willebrand factor and cytokeratin were used to confirm the purity of mesangial cell cultures and absence of contaminating endothelial and epithelial cell types.

\section{Treatment of mesangial cell cultures with experimental agents}

For all experiments, mesangial cells were serum-starved overnight in DMEM containing 0.5\% FBS prior to treatment with experimental agents. Before adding the experimental agents, cell monolayers were washed twice with serum free DMEM- medium (SFM) and incubated at $37^{\circ} \mathrm{C}$ in a humidified cell culture incubator for $2 \mathrm{hrs}$ in the presence of $0.1 \%$ FBS containing DMEM-F/12 medium. IgA $(0-10 \mu \mathrm{g} / \mathrm{ml})$ was added to the cell cultures in the presence or absence of FBS (5\%) or IGF-1(10-100 ng/ml). Following the addition of experimental agents, cells were incubated in cell culture incubator for another $24 \mathrm{hrs}$ at $37^{\circ} \mathrm{C}$.

BrdU Incorporation (DNA Synthesis) in mesangial cells

DNA synthesis in cultures of mesangial cells in response to IgA and growth factors were assayed via measuring bromodeoxyuridine (BrdU) incorporation in to cellular DNA using kits purchased from Calbiochem. Briefly, incorporation of Brdu in vitro was measured in cells after incubation with experimental agents for 24 hours at $37^{\circ} \mathrm{C}$, in the media supplemented with $10 \mu \mathrm{M}$ BrdU. The cells were then stained with a peroxidase-labeled antibody against BrdU. The absorbance of the samples at $450 \mathrm{~nm}$ was measured using a microplate reader.

\section{RNA isolation and reverse transcription}

Total RNA was extracted from cultured mesangial cells with RNA extraction kit based on use of guanidinium thiocyanate, lithium chloride and cesium triflouroacetate. Isolated RNA was of high quality and was used immediately for synthesis of first strand cDNA according to protocols from Clonetech's SMART PCR cDNA synthesis kit.

\section{Quantitative PCR detection of $m R N A$ for IGF-1R}

After the first strand synthesis, real-time PCR was done using $8 \mu \mathrm{l}$ cDNA, $10 \mu \mathrm{l}$ SYBR green PCR master mix (Bio-Rad Laboratories, Hercules, CA) and forward and reverse primers $(10 \mu \mathrm{M} / \mathrm{ml}$ ) (Integrated DNA Technologies, San Diego, CA) in a real-time PCR system (CFX96; Bio-Rad Laboratories). The primer sequences used were IGF-1R; forward 5'-GGGAATGGAGTGCTGTATG-3', reverse 5'-CACAGAAGCTTCGTTGAGAA-3'. The specificity of the primers was analyzed by running a melting curve. The PCR cycling conditions used were $5 \mathrm{~min}$ at $95^{\circ} \mathrm{C}$ for initial denaturation, 40 cycles of $30 \mathrm{~s}$ at $95^{\circ} \mathrm{C}, 30 \mathrm{~s}$ at $58^{\circ} \mathrm{C}$ and $30 \mathrm{~s}$ at $72^{\circ} \mathrm{C}$. Each realtime PCR was carried out using three individual samples in triplicates, and the threshold cycle values were averaged. Calculations of relative normalized gene expression were done using the Bio-Rad CFX manager software.

\section{IGF-1 Assay}

To assess the cumulative production of IGF-1 by GMC in response to IgA treatment, IGF-1 levels were measured in culture supernatants combined with cell homogenates using commercially available ELISA kits from Assay Design Inc. 


\section{Kidney Blood Pressure Research}

Statistical analysis

Data were analyzed using student's t test for significance of variance between different groups of the study.

\section{Results}

Effect of IgA on Bromodeoxyuridine (BrdU) incorporation (an index of DNA synthesis) in glomerular mesangial cells

Brdu incorporation was measured in cell cultures of renal mesangial cells following treatment with various concentrations $(0-10 \mu \mathrm{g} / \mathrm{ml})$ of $\operatorname{IgA}$ for $24 \mathrm{hrs}$. Figure 1 shows that BrdU incorporation was significantly $(\mathrm{p}<0.01)$ more in cells treated with IgA (5.0 -10.0 $\mu \mathrm{g} / \mathrm{ml}$, concentrations reported to cause glomerulonephritis in in vivo studies) as compared to cells without any treatment irrespective of the presence or absence of a mitogen (FBS), and the effect of IgA seems more pronounced at the highest concentration used.

Effect of IgA on growth factorinduced DNA synthesis in glomerular mesangial cells

Mesangial cell cultures were treated with varying concentrations of IGF-1 (10-100 ng/ml) for $24 \mathrm{hrs}$ in the absence and presence of IgA $(10 \mu \mathrm{g} / \mathrm{ml})$ and BrdU incorporation was measured. IGF-1 significantly ( $p<0.01$ when compared with control) increased BrdU incorporation in glomerular mesangial cell cultures (Figure 2) and co-incubation of cells with IgA markedly enhanced the growth factor-induced DNA synthesis ( $p<0.01)$, however incremental effect of IgA was more pronounced at higher

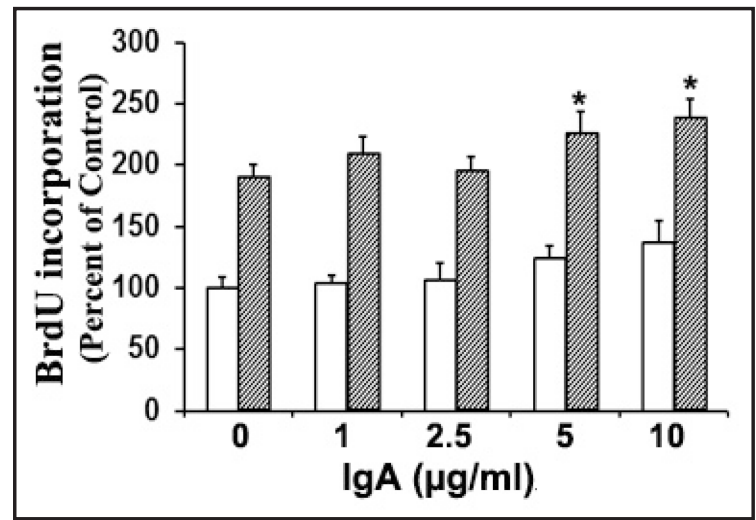

Fig. 1. BrdU incorporation into GMC following $24 \mathrm{hr}$ treatment with varying concentrations of IgA in the absence (open bars) or presence (Dark bars) of 5\% FBS. Values are Mean \pm SD of six measurements. ${ }^{*} p<0.01$ when compared with control (without IgA or mitogen treatment).

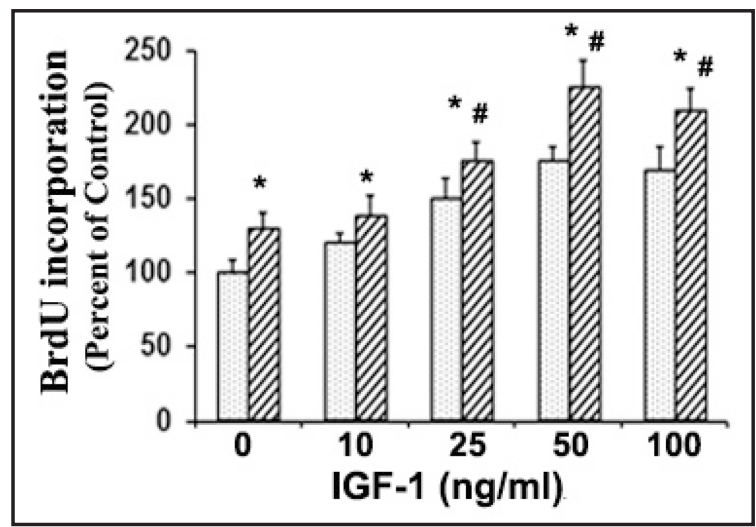

Fig. 2. Dose response effect of IGF-1 on BrdU incorporation into GMC following $24 \mathrm{hr}$ treatment in the absence (open bars) or presence (dark bars) of $10 \mu \mathrm{g} / \mathrm{ml}$ of IgA. Values are Mean \pm SD of six measurements. ${ }^{*} p<0.01$ when compared with control (without IgA or IGF-1). \#p $<0.01$ when compared with IgA treated cells without IGF-1.

concentrations of IGF-1. This co-mitogenic response of IgA and IGF-1 is an intriguing suggesting that IgA might be regulating the expression of IGF-1 and or IGF-1 receptor. To further assess the involvement of IGF-1 receptor and its signaling, co-mitogenic effect of IgA and IGF-1 was assessed in cells that were pretreated with IGF-1 receptor antibody $(25 \mu \mathrm{g} /$ $\mathrm{ml}$ ) or genistein $(50 \mu \mathrm{M})$, a tyrosine kinase inhibitor. Both IGF-1R antibody and genistein significantly $(\mathrm{p}<0.01)$ blocked the co-/mitogenic effect of IgA and or IGF-1 (Figure 3). An isotype matched antibody used as a control for the anti-IGF $1 \mathrm{R}$ antibody did not have any significant influence on IgA-induced co-/mitogenic effects (data not shown).

\section{Effect of IgA on IGF-1 and IGF-1 receptor}

In view of our findings that BrdU incorporation was significantly more in IgA treated cells irrespective of the presence or absence of a mitogen, we examined the effect of IgA 


\section{Kidney \\ Blood Pressure Research}

on IGF-1 levels and the gene expression of IGF-1 receptor in mesangial cells. IGF1 content was significantly $(p<0.05)$ more in supernatants and homogenates of cells treated with $10 \mu \mathrm{g} / \mathrm{ml}$ of IgA as compared to untreated cells (Figure 4). Quantitative real-time PCR revealed that amount of IGF-1R mRNA was significantly increased in cells following treatment with $\operatorname{IgA}$ in the presence and absence of IGF-1 (Figure 5). Treatment of cells with IGF- 1 also significantly ( $p$ > 0.01 ) increased the transcription of IGF$1 \mathrm{R}$ gene and IgA further potentiated the IGF-1-induced IGF-1R transcription.

\section{Discussion}

Glomerulosclerosis due to enhanced mesangial cell proliferation is a well known pathological event of IgA-mediated nephropathy that involves role of several growth factors including IGF-1. Though IGF-1, a major growth factor involved in development of children, is believed to participate in development and progression of IgAN, exact mechanism of its action has remained unclear. This ex vivo study demonstrates that IgA enhances the mitogenic activity of IGF-1 through modulation of its receptor in cultured renal mesangial cells, thus suggesting a new insight into molecular mechanism of IgAN pathogenesis in children. Though the role of monomeric, polymeric or secretory forms of IgA in development of nephropathy is controversial and debatable, this study illustrates that purified secretory form of IgA enhances mitogenic responses in cultures of renal mesangial cells. Mitogenic effect of serum growth factors mainly PGDF and EGF has been well documented with regard to in vivo and in vitro studies on proliferation of renal mesangial cells and its importance in renal dysfuntion due to glomerulosclerosis [18, 19]. PDGFinduces mitogenic effects and its role in potent co-mitogenic effect of IgA on IGF-1-induced BrdU incorporation in this study is quite intriguing.

Observed co-mitogenic effect of IgA and IGF-1 on GMC cultures could be speculated to occur through either an enhanced production of IGF-1or through induction/stimulation 


\section{Kidney \\ Blood Pressure Research}

of its receptor, IGF-1R, besides any other possible mechanisms. The fact that pretreatment of cells with IGF-1RAb markedly blocked the co-/mitogenic effect of IgA and IGF-1 strengthens the notion that stimulation of IGF-1R might be involved in IgA-mediated glomerulosclerosis.

It has been suggested earlier that IGF-1 signaling might play an important role in renal fibrosis and regulation of the proliferation of mesangial cells and podocytes, and single nucleotide polymorphism studies have observed associations between the IGF-1/1R pathway, susceptibility to IgAN, and the pathologic progression of IgAN [22]. Our findings that IgA increases the levels of IGF-1 in culture supernatants and cell homogenates strongly indicates that IGF-1and its receptor-mediated signaling might have a potent role in pathogensis of IgAN. Most IGF actions are mediated by the tyrosine

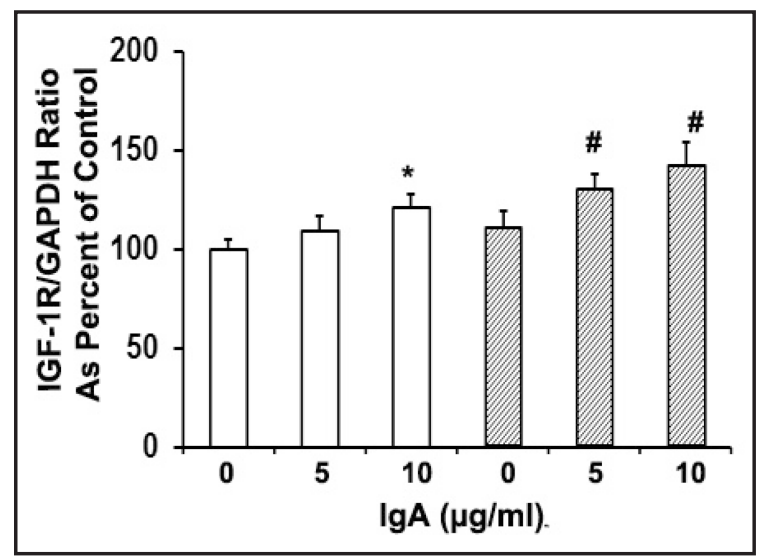

Fig. 5. Ratio of the IGF-1R and GAPDH ( as determined by quantitative RT- PCR) in GMC following $24 \mathrm{hr}$ treatment with IgA in the absence (open bars) or presence (shaded bars) of IGF-1. Values are Mean \pm SD of six measurements. ${ }^{*} p<0.01$ when compared with control (without IgA treatment). \#p $<0.01$ when compared with respective IgA treated cells without IGF-1.

kinase IGF-1 receptor. Activation of IGF-1receptor signaling has been implicated in development of several kidney diseases that include diabetic nephropathy and renal carcinomas $[23,24]$, and IGF-1 receptor inhibitors have been developed for use as therapeutic tools [25] against progression of these proliferative diseases.

Though significance and possible involvement of IGF-1 receptor in IgAN has been suggested earlier, yet effect of IgA on IGF-1 receptor has remained unexplored. Our findings that IgA increases mRNA levels of IGF-1R in GMC cultures strongly suggests modulation of receptor gene expression during progression of IgAN. Enhanced transcription of IGF-1R gene by IgA alone and its further potentiation in the presence of IGF-1 indicates a selective stimulation of IGF-1/IGF-1R pathway during mesangial cell proliferation in development and progression of IgAN. Observed enhancement in IGF-1R gene transcription might have occurred in response to increased production of IGF-1 in IgA-stimulated cells. Simultaneous or complimentary activation of IGF-1/IGF1-1 by IgA as observed in this ex vivo study might exert an autocrine or paracrine effects on GMC to induce proliferation in vivo during development of IgAN.

\section{Conclusion}

IgA might have a selective potent stimulatory effect on IGF-1 and its receptor, besides other mechanisms to induce proliferation of GMC during development and progression of IgAN.

\section{Disclosure Statement}

Authors do not have any conflict of interest.

\section{Acknowledgement}

Authors would like to Mrs. Heba Dalvi for her technical support. This study was supported by project number Mk 01/14 funded by the Research Sector Kuwait University, Kuwait. 


\section{Kidney \\ Blood Pressure Research}

Al-Eisa/Dhaunsi: IgA Enhances IGF-1 Activity in Renal Mesangial Cells

\section{References}

1 Donadio JV, Grande JP: IgA nephropathy. N Engl J Med 2002;347:738-748.

-2 Ghani AA, Al-Waheeb S, Al-Homoud E, Al-Helal B, Hussain N: Clinical and histopathological spectrum of IgA nephropathy in Kuwait. Ann Saudi Med 2011;31:152-157.

3 Moriyama T, Tanaka K, Iwasaki C, Oshima Y, Ochi A, Kataoka H, Itabashi M, Takei T, Uchida K, Nitta K: Prognosis in IgA nephropathy: 3-year analysis of 1012 Patients at a single center in Japan. PLoS One 2014;9:e917576.

4 Delos Santos NM, Wyatt RJ: Pediatric IgA nephropathies: clinical aspects and therapeutic approaches. Semin Nephrol 2004;24:269-286.

5 Yu HH, Chiang BL: Diagnosis and classification of IgA nephropathy. Autoimmun Rev 2014;13:556-559.

6 Tan W, Li W, Zou G, Zhang C, Fang J: Clinicopathological features and outcomes of IgA nephropathy with hematuria and/or minimal proteinuria. Kidney Blood Pressure Res 2015;40:200-206.

$>_{8}$ Alchi B, Jayne D: Membranoproliferative glomerulonephritis. Pediatr Nephrol 2010;25:1409-1418. Gomez-Guerrero C, Hernandez-Vargas P, Lopez-Franco O, Ortiz-Munoz G, Egido J: Mesangial cells and glomerular inflammation: from the pathogenesis to novel therapeutic approaches. Curr Drug Targets Inflamm Allergy 2005;4:341-351.

9 Kawasaki Y: Mechanism of onset and exacerbation of chronic glomerulonephritis and its treatment. Pediatr Int 2011;53:795-806.

-10 Oortwijn BD, Roos A, Royle L, van Gijlswijk-Janssen DJ, Faber-Krol MC, Eijgenraam JW, Dwek RA, Daha MR, Rudd PM, van Kooten C: Differentila glycosylation of polymeric and monomeric IgA:a possible role in glomerular inflammation in IgA nephropathy. J Am Soc Nephrol 2006;16:3529-3539.

11 Eijgenraam JW, Oortwijn BD, Kamerling SW, de Fijter JW, van den Wall Bake AW, Daha MR, van Kooten C: Secretory immunoglobulin A (IgA) responses in IgA nephropathy patients after mucosal immunization, as part of polymeric IgA response. Clin Exp Immunol 2008;152:227-232.

12 Abboud HE: Mesangial cell biology. Exp Cell Res 2012;318:979-985.

13 Nakagawa T, Inoue H, Sasahara M: Platelet-derived growth factor and renal disease. Curr Opin Nephrol Hypertens 2012;21: 80 -85.

14 Worawichawong S, Worawichawong S, Radinahamed P, Muntham D, Sathirapongsasuti N, Nongnuch A, Assanatham M, Kitiyakara C: Urine Epidermal Growth factor, Monocyte Chemoattractant Protein-1 or Their Ratio as Biomarkers for Interstitial Fibrosis and Tubular atrophy in Primary Glomerulonephritis. Kidney Blood Press Res 2016;41:997-1007.

15 Caliskan Y, Ozluk Y, Celik D, Oztop N, Aksoy A, Ucar AS, Yazici H, Kilicaslan I, Sever MS: The Clinical Significance of Uric Acid and Complement Activation in the progression of IgA Nephropathy. Kidney Blood Press Res 2016;41:148-157.

16 Hahn WH, Suh JS, Cho BS: Polymorphisms of insulin-line growth factor-1 (IGF-1) and IGF-1 receptor (IGF1R) contribute to pathologic progression in childhood IgA nephropathy. Growth Factors 2011;29:8-13.

17 Peer A, Averbukh Z, Berman S, Modia D, Averbuck M: Contrast media augmented apoptosis of cultured renal mesangial, tubular epithelial, endothelial and hepatic cells. Invest Radiol 2003;38:177-182.

18 Bartlett CS, Jeansson M, Quaggin SE: Vascualr Growth Factors and Glomerular Disease. Annu Rev Physiol 2016;78:437-461.

19 Kok HM, Falke LL, GoldSchmeding R, Nguyen TQ: Targeting CTGF, EGF and PDGF pathways to prevent progression of kidney disease. Nat rev Nephrol 2014;10:700-711.

20 Floege J, van Roeyen C, Boor P, Ostendorf T: The role of PDGF-D in mesangioproliferative glomerulonephritis. Contrib Nephrol 2007;157:153-158.

21 Wada J, Sugiyama H, Makino H: Pathogenesis of IgA nephropathy. Semin Nephrol 2003;23:556-563.

22 Nakamura T, Ebihara I, nagaoka I, Takahashi T, Tomino Y, Koide H: Abnormal regulation of insulin-like growth factor gene expression in peripheral blood mononuclear cells from patients with IgA nephropathy. Am J Nephrol 1992;12:292-302.

23 Bach LA, Hale LJ: Insulin-like growth factors and kidney disease. Am J Kidney Dis 2015;65:327-336.

-24 Troib A, Landau D, Youngren JF, Kachko L, Rabkin R, Segev Y: The effects of type1 IGF receptor inhibition in a mouse model of diabetic kidney disease. Growth Horm IGF Res 2011;21:285-291.

25 Oh Y: The insulin-like growth factor system in chronic kidney disease: Pathophysiology and therapeutic opportunities. Kidney Res Clin Pract 2012;31:26-37. 